\title{
A "State of the Art" environmental monitoring and sensing network for the Nile River in Egypt
}

\author{
S. Abdel-Gawad ${ }^{1}$, H. Khan ${ }^{2}$ \& A. A. Khan ${ }^{2}$ \\ ${ }^{I}$ National Water Research Center, \\ Ministry of Water Resources and Irrigation, Egypt \\ ${ }^{2}$ Water Resources Management Division, Newfoundland and Labrador, \\ Department of Environment and Conservation, Canada
}

\begin{abstract}
The Nile River in Egypt is the primary source of water for a multitude of strategically important water uses such as drinking, fishing, industrial, livestock and irrigation and there is a critical need to ensure the security of the Nile River against any natural or anthropogenic threats. Addressing this need, a "state of the art" environmental monitoring and sensing system is being implemented for the Nile River in Egypt through a NATO "Science for Peace" Project. The "Science for Peace" project, initiated in July 2007, is setting up an environmental security and water resources management system for the Nile River using a real time water quality warning and communication. The real time water quality warning will be provided through a four station Real Time Water Quality monitoring index network complemented with an automated weather station with a central command centre. In parallel, an Egyptian Water Quality Index, a critical tool for water resources management, will be developed to evaluate and communicate the suitability of water bodies in Egypt for various uses such as drinking, irrigation, livestock, aquatic life and recreation. This paper outlines the concept behind the environmental monitoring network, its scope, and environmental benefits. The paper also outlines how Egypt plans to expand the index network to address trans-boundary monitoring of the Nile River.

Keywords: environmental security, environmental monitoring network, hydrolab datasonde, real time water quality monitoring, water quality index, water uses, communication command centre, and trans-boundary water governance.
\end{abstract}




\section{Introduction}

The history, culture, current and future socio-economic status, and environmental sustainability of Egypt and its people is intricately linked with the Nile River. In Egypt the Nile River is the primary source of water for a multitude of strategically important water uses such as drinking, fishing, industrial, livestock and irrigation. Approximately 85 percent of the Nile River water is used for irrigation, 8 percent for drinking and 7 percent for industrial. Fishing, aquaculture, and navigation are in-stream uses of the Nile River water. The water from the Nile is conveyed to the users through a vast network of canals. Wastewater and agricultural drainage water from these uses are collected by drains and are often returned to the Nile River as inflows.

The economic and social importance of ensuring the security of the Nile River against any natural or anthropogenic threats cannot be overemphasized. Approximately 99 percent of the population of Egypt (total population is approximately 76 million) lives within the Nile Valley and Delta, which constitutes less than 5.5 percent of Egypt's total land area. The area of the Nile Delta itself is about $25,000 \mathrm{~km}^{2}$ with about 35 million inhabitants. Any disruption or impairment from natural or anthropogenic threats cannot be without far reaching economic and social implications.

In view of the above, there is an urgent need to establish a pilot system in Egypt to monitor its strategic water bodies (the Nile River and its vast network of canals and drains) on a real time basis against any natural or anthropogenic threats. The proposed real time water monitoring and reporting system will allow senior water managers to protect the integrity of Egypt's vital water resources, as well as to report the suitability of water for designated beneficial water uses. Once the pilot system has been implemented and tested, the National Water Research Centre (NWRC) of the Egypt Ministry of Water Resources and Irrigation (MWRI), in collaboration with international funding agencies, would likely expand this system to the entire Nile River system.

\section{Current state of water resources and water monitoring in Egypt}

Based on the assessment of the available data, the water supply-demand situation in Egypt appears to be changing with time. Table 1 shows the current water resources in the year 2006 for Egypt. As shown in the table a major portion of the water resources originates from the Nile River.

Egypt is experiencing rapid population and urbanization growth which leads to additional demand on its limited water resources [1]. The total population has increased from 33 million in 1965 to 76 million in 2007. It is anticipated that by year 2025 Egypt's total population will be about 100 million thus, increasing the demand for scarce water and arable land. Due to limited water resources, the increase in population reduces the per capita water share. Based on the analysis of the available data, per capital water share has changed from 1,700 cubic 
Table 1: $\quad$ Current water resources for the year 2006.

\begin{tabular}{|c|c|}
\hline Water Resources & $\begin{array}{c}\text { Measurement in } \\
\text { Billion Cubic Meters (BCM) }\end{array}$ \\
\hline River Nile & 55.5 \\
\hline Agriculture Drainage water reuse in the delta & 5.2 \\
\hline Groundwater in the valley and the delta & 4.8 \\
\hline Rainfall and Floods & 1.0 \\
\hline Treated Wastewater Reuse & 0.7 \\
\hline Groundwater in the deserts and Sinai & 0.57 \\
\hline Total & 67.77 \\
\hline
\end{tabular}

meters per year in 1950 to 1,000 cubic meters per year in 2000 . The substantial reduction in the per capita water share during 1950 to 2000 highlights the need for strategic actions for the management of limited water resources.

Since the construction of the High Aswan Dam (HAD) in 1964, the water quality of the Nile became primarily dependent on the water quality and ecosystem characteristics of Lake Nasser reservoir and less dependent on the water quality of the upper reaches of the Nile.

Downstream changes in Nile water quality are primarily due to (i) the hydrodynamic regime of the river regulated by the different barrages, (ii) agricultural return flow, and (iii) domestic and industrial waste discharges including oil and waste from the river fleet which comprises over 9000 units.

Thus, a water quality monitoring program, with a national perspective, was developed and implemented which is based on an integrated approach to water quality data collection, analysis, interpretation and coordination. The ultimate goal of this national water quality monitoring program is to provide decision makers with information about the present status of water quality.

The current water monitoring network in Egypt comprises of 232 monitoring stations on Lake Nasser, Nile River, Irrigation Canals and Drainage Canals. Figure 1 shows the location of water monitoring stations. Currently most of the sites along the Nile River are monitored by the Ministry of Water Resources and Irrigation (MWRI) and its research wing - the National Water Research Center (NWRC) for water quality and water quantity on a pre-defined frequency. Four of these sites are under semi continuous water quality monitoring on the El Salam Canal. However, these four sites are based on an older individual sensor technology. Measurements are not always in-situ, and are not set up for real time water data reporting. Furthermore there is no central command centre to coordinate the Real Time Water Monitoring data. This system is also not conducive to any early warning application and thus cannot set into motion any corrective measures by responsible authorities.

From the water resources management perspective while water data is currently collected on a regular basis, appropriate communication tools do not exist to convert the raw water data into information and then knowledge (i.e. to convert complex water quality data into scores and rankings that are easy to 


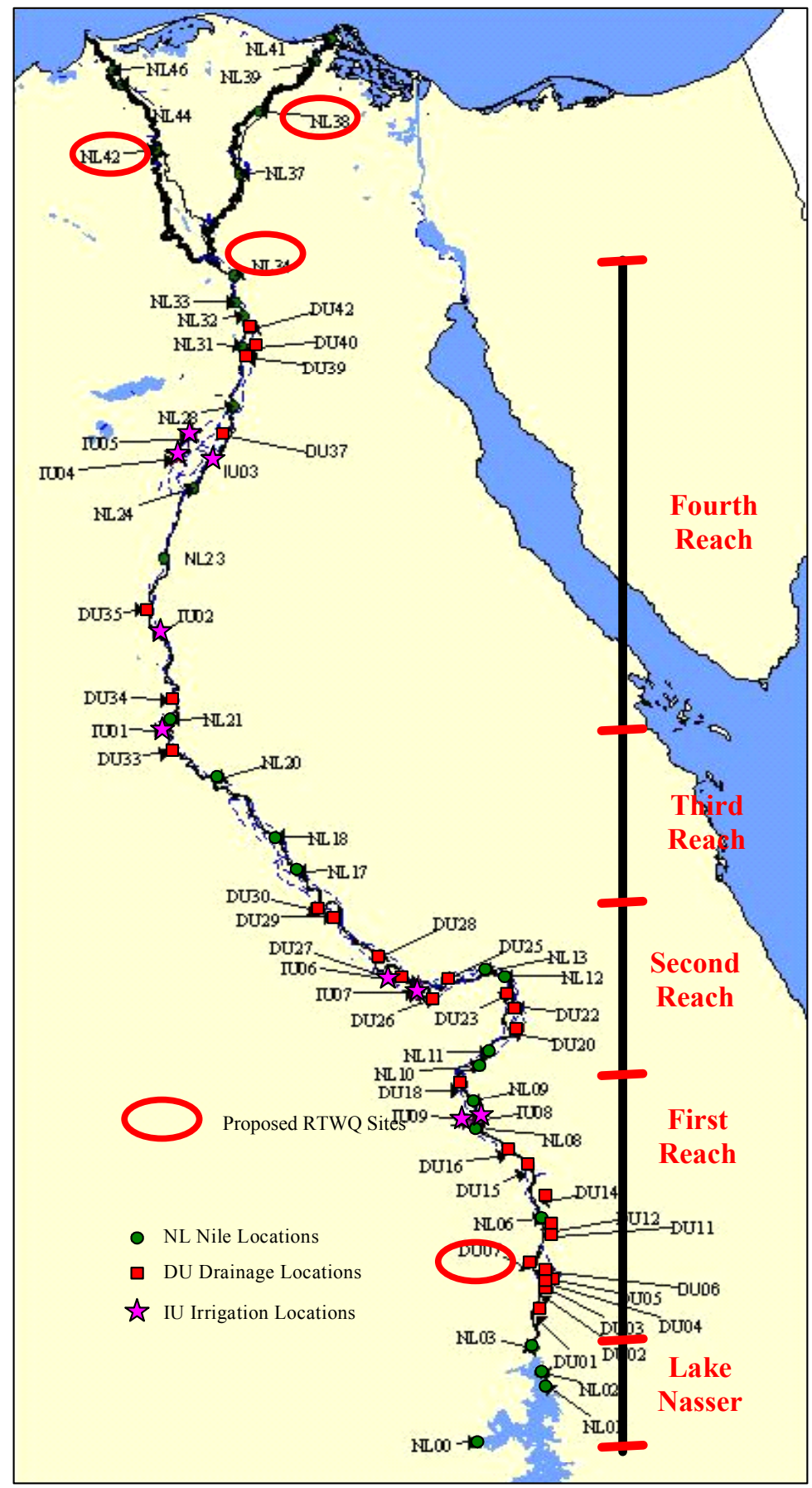

Figure 1: Water quality monitoring sites. 
communicate). There is no exceedance base computation for the different water uses (drinking, fishing etc.). The conversion of raw water quality data into information and then knowledge is a core component of water resources management and is critical for effective decision making by executive, politicians and the general public.

\section{Proposed water monitoring and reporting system}

The proposed water monitoring and reporting system comprises of four real time water monitoring stations, one automated weather station, upgrade to four existing semi continuous water monitoring stations on El Salam Canal, set-up of data collection and reporting command centre and the development and implementation of water quality index to access and report the suitability of water for designated beneficial water uses. The proposed system will allow the management of Egypt's water resources using a real time pro-active approach.

The project proposes to establish four real time water quality monitoring sites which are selected based on their strategic locations. The four sites are NL03, NL34, NL39 and NL 42.

NL03 is the first monitoring location on the Nile River. This site is of strategic importance as it is the reference point for the quality of water entering the Nile River from Lake Nasser. Downstream water uses include drinking water use, irrigation, livestock, fishing, tourism and navigation. NL34 is located in the Nile River at the intake of the Ismailia Canal next to the NWRC. NL34 is of strategic importance as the Ismailia Canal is used as the principal drinking water supply for the Cities of Cairo, Ismailia, Port Said and Suez.

NL39 is on the Damietta Branch of the Nile River at the intake of the strategically and socio-economically important El Salam Canal. From a water resources management perspective, this point represents the cumulative impact of several drainage inputs along the Damietta Branch and is a site used for fishing. It also represents the starting water quality of the El Salam Canal which is the primary source of irrigation water for agriculture in the Sinai Peninsula. NL42 is a strategically important site on the Rossetta Branch that is located at the drinking water intake of the town of Benowar. There are drinking water intakes of other small communities located downstream of this site. In-stream uses at the site include fishing. There are almost annual incidents of fish kills reported in this segment of the Rossetta branch between NL 34 and NL 42.

Figure 2 shows the architecture of the proposed real time water data collection and reporting system [2]. In this system, at first raw data for water, such as level, pH, Dissolved Oxygen, water temperature, ammonium, nitrate etc., is collected at regular intervals from installed sensors in the real time monitoring sites. The automated weather station collects weather related data such as air temperature, relative humidity, air pressure etc. The collected data is transferred through cellular or dial-up access on a near real time basis to the NWRC server. The collected data is used to create a time series graph for individual parameters which is updated every time new data is acquired. A user with a computer and 
Installed Sensor Types

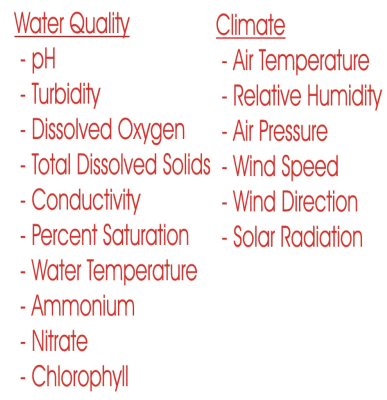

Hydrometric

- Stage
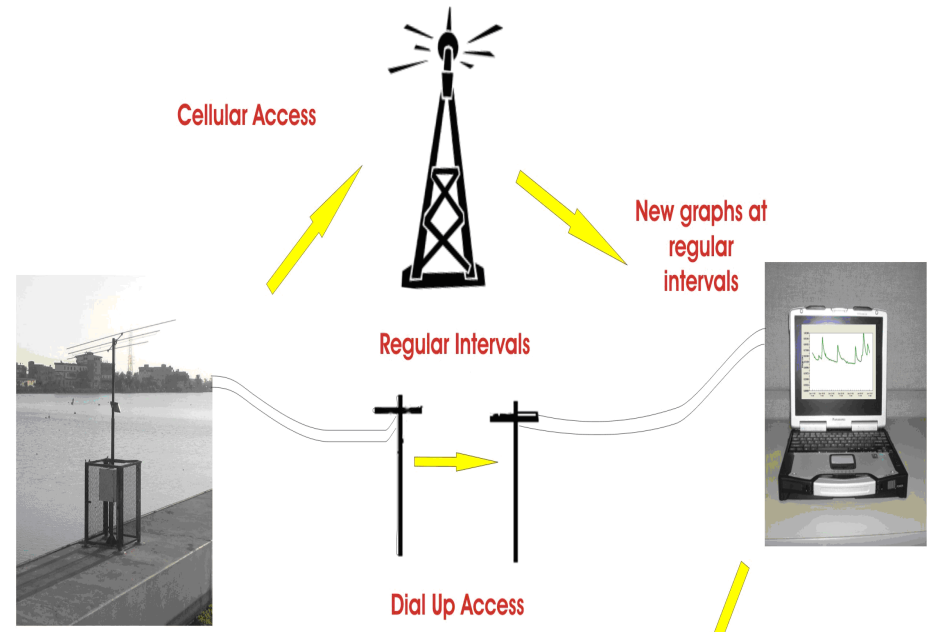

NWRC Intranet Web Server

Figure 2: The real time water quality monitoring for the river Nile.

internet access will be able to view these graphs and monitor the sites on a near real time basis. Any unusual activity within the sites will be indicative by the extreme values of the collected parameters within these graphs.

The Egyptian Water Quality Index (EWQI) will be based on the Canadian Council of Ministers of Environment (CCME) Water Quality Index Calculator [3]. Egyptian Water Quality Index will be developed for: (i) evaluating the suitability of various water bodies for designated beneficial uses such as drinking, irrigation, livestock, aquatic life and recreation, and (ii) converting water quality data into information and into knowledge. The EWQI will be developed in parallel with the real time water quality network.

The detailed formulation of the WQI is described in the Canadian Water Quality Index 1.0 - Technical Report [4]. It consists of three measures which are described as follows: 
Scope, $F_{1}$

The measure for scope is $F_{1}$. This represents the extent of water quality guideline non-compliance over the time period of interest.

$$
F_{1}=\left(\frac{\text { Number of failed variables }}{\text { Total number of variables }}\right) \times 100
$$

Frequency, $F_{2}$

The measure for frequency is $F_{2}$. This represents the percentage of individual tests that do not meet objectives ("failed tests").

$$
F_{2}=\left(\frac{\text { Number of failed tests }}{\text { Total number of tests }}\right) \times 100
$$

Amplitude, $F_{3}$

The measure for amplitude is $F_{3}$. This represents the amount by which failed tests do not meet their objectives. This is calculated in three steps:

Step 1-Calculation of Excursion: Excursion is the number of times by which an individual concentration is greater than (or less than, when the objective is a minimum) the objective.

When the test value must not exceed the objective:

$$
\text { excursion }_{\mathrm{i}}=\left(\frac{\text { Failed Test Value }_{\mathrm{i}}}{\text { Objective }_{\mathrm{j}}}\right)-1
$$

When the test value must not fall below the objective:

$$
\text { excursion }_{\mathrm{i}}=\left(\frac{\text { Objective }_{\mathrm{j}}}{\text { Failed Test Value }_{\mathrm{i}}}\right)-1
$$

Step 2- Calculation of Normalized Sum of Excursions: The normalized sum of excursions, nse, is the collective amount by which individual tests are out of compliance. This is calculated by summing the excursions of individual tests from their objectives and dividing by the total number of tests (both those meeting objectives and those not meeting objectives).

$$
n s e=\frac{\sum_{\mathrm{i}=1}^{\mathrm{n}} \text { excursion } \mathrm{i}}{\text { Number of tests }}
$$

Step 3-Calculation of $\mathrm{F}_{3}: \mathrm{F}_{3}$ is calculated by an asymptotic function that scales the normalized sum of the excursions from objectives to yield a range from 0 to 100 .

$$
\mathrm{F}_{3}=\left(\frac{n s e}{0.01 n s e+0.01}\right)
$$


The WQI is then calculated as:

$$
\mathrm{WQI}=100-\left(\frac{\sqrt{\mathrm{F}_{1}^{2}+\mathrm{F}_{2}^{2}+\mathrm{F}_{3}^{2}}}{1.732}\right)
$$

The WQI values are then converted into rankings by using the categorization schema presented in Table 2. By this process the CCME WQI converts raw water quality data into information (how many parameters exceeded the guidelines, how frequently and by what amplitude) and then into knowledge (the water is Excellent, Good, Fair or Poor for drinking water use etc.).

The CCME WQI formulation has been automated in various spreadsheet programs. CCME WQI calculators are available from CCME (http://www.ccme.ca/initiatives/water.html?category_id=42) and the Newfoundland and Labrador Department of Environment and Conservation (http://www.gov.nf.ca/Env/env/waterres/Surfacewater/WQI/CanadianWQI.asp) web sites. The NL calculator uses the same formulation as the CCME calculator but it includes additional features and tools such as the ability to compute WQ indices for up to eight different water uses simultaneously, generation of Site Specific Guidelines for use in the WQI computations, parameter flagging, a customizable index categorization schema and other advanced sensitivity analysis options.

\section{Table 2: $\quad$ CCME WQI categorization schema.}

\begin{tabular}{|l|l|l|}
\hline Rank & $\begin{array}{l}\text { WQI } \\
\text { Value }\end{array}$ & Description \\
\hline Excellent & $\begin{array}{l}95- \\
100\end{array}$ & $\begin{array}{l}\text { Water quality is protected with a virtual absence of } \\
\text { threat or impairment; conditions very close to natural or } \\
\text { pristine levels; these index values can only be obtained } \\
\text { if all measurements are within objectives virtually all of } \\
\text { the time }\end{array}$ \\
\hline Good & $80-94$ & $\begin{array}{l}\text { Water quality is protected with only a minor degree of } \\
\text { threat or impairment; conditions rarely depart from } \\
\text { natural or desirable levels. }\end{array}$ \\
\hline Fair & $65-79$ & $\begin{array}{l}\text { Water quality is usually protected but occasionally } \\
\text { threatened or impaired; conditions sometimes depart } \\
\text { from natural or desirable levels }\end{array}$ \\
\hline Marginal & $45-64$ & $\begin{array}{l}\text { Water quality is frequently threatened or impaired; } \\
\text { conditions often depart from natural or desirable levels }\end{array}$ \\
\hline Poor & $0-44$ & $\begin{array}{l}\text { Water quality is almost always threatened or impaired; } \\
\text { conditions usually depart from natural or desirable levels }\end{array}$ \\
\hline
\end{tabular}

\section{Project governance}

The project is implemented jointly by the Department of Environment and Conservation of Newfoundland and Labrador, Canada and the National Water 
Research Centre (NWRC) of the Ministry of Water Resources and Irrigation, Egypt under the funding and supervision of NATO. The team members for this project consists of a NATO country (Canada) project director (NPD) and two project co-directors (NPCD), a NATO partner country (Egypt) project director (PPD), two project co-directors (PPCD) and ten young scientists. One of the NPCD is represented by the National Survey of Canada and while one PPCD and three of the ten young scientists is represented by the Cairo University. One of the key objectives of the project is capacity building among young scientists in Egypt through training and professional development.

\section{Key outcomes}

The project will transform the current water monitoring and reporting system to a holistic approach that will encompass all aspects of integrated water resources management from data collection, analysis, reporting, response and mitigation. This holistic approach will give Egypt the ability to pro-actively identify and respond to both security and water quality management issues. Deterioration of water quality and water supply management are two of the major issues faced by Egypt which if not addressed in time will have adverse socio-economic and environmental implications.

The project outcomes would provide valuable scientific product to international funding agencies to finance a similar type of network throughout the Nile River basin and use the real time water data for trans-boundary water governance in the region.

\section{Acknowledgements}

This project is fully funded by the North Atlantic Treaty Organization (NATO) under the theme of water security for the Nile River (SfP-982630). The Project Directors and Co-directors are grateful to the NATO for its support and funding for the project.

\section{References}

[1] Abdel-Gawad, S T. Water Quality Challenges Facing Egypt. Water Policy Reform Conference, June 24-25, 2002.

[2] Near Real Time Stream flow and Climate Information, Online www.env.gov.nl.ca/wrmd/hydro_model.asp

[3] Khan H, Khan A A, Hall S, The Canadian Water Quality Index: A Tool for Water Resources Management. Midterm International Conference, Asian Institute of Technology, pp. 349-355, 2005.

[4] CCME. Canadian Water Quality Guidelines for the protection of aquatic life: Canadian Water Quality Index 1.0 Technical Report. In Canadian Environment quality guidelines 1999. 2001. 